\title{
Production of Liquid Bio fertilizer by using Azotobacter Species and their Effect on Plant Growth
}

\author{
Sumanto Prasad Barat ${ }^{1}$, Abhishek Gupta ${ }^{2}$, Dharmendra Singh ${ }^{2}$, Arpita Srivastav $^{2}$, \\ Summit Kumar Srivastav ${ }^{1}$, Ravi Kumar ${ }^{2}$, Pooja Singh ${ }^{2}$, Nikhat firdous ${ }^{2}$ and Neelam Soni ${ }^{2}$ \\ ${ }^{1}$ Vinoba Bhave University (J.H.), India \\ ${ }^{2}$ Center for Microbiology and Biotechnology (CMBT) Research \& Training Institute, \\ Bhopal (M.P.), India \\ *Corresponding author
}

\begin{tabular}{|c|c|}
\hline & A B S T R A C T \\
\hline $\begin{array}{l}\text { Ke y w or d s } \\
\text { Azotobacter, } \\
\text { Liquid Bio } \\
\text { fertilizer, } \\
\text { Plant Growth. }\end{array}$ & $\begin{array}{l}\text { Due to the function of Azotobacter in nitrogen fixation and to their probable } \\
\text { biotechnological applications, there are few challenges in developing an effectual } \\
\text { approach for the selective isolation of these micro-organisms from soil. One } \\
\text { hundred ninety-six Gram-negative strains were isolated from } 35 \text { soils sampled in } \\
\text { central Italy, by using and comparing three different methods. The screening of soil } \\
\text { samples by means of soil paste-plate method mutual with isolation on mannitol- }\end{array}$ \\
\hline Article Info & $\begin{array}{l}\text { agar proved to be the finest strategy in terms of consistency and selectivity. } \\
\text { Moreover preliminary recognition of free-living nitrogen-fixing isolates on }\end{array}$ \\
\hline $\begin{array}{l}\text { Accepted: } \\
\text { 22 June } 2016 \\
\text { Available Online: } \\
\text { 10 July } 2016\end{array}$ & $\begin{array}{l}\text { the isolates with Azotobacter-like morphology on such a average were } \\
\text { presumptively identified as members of the family Azotobacteriaceae, by means of } \\
\text { amplified ribosomal DNA restriction analysis. }\end{array}$ \\
\hline
\end{tabular}

\section{Introduction}

Microorganisms employed to improve availability of nutrients, viz, nitrogen (by fixing atmospheric $\mathrm{N}_{2}$ and phosphorus (by solublizing soil phosphorus), to the crops are called biofertilizer the various microorganism having realized/prospective application as biofertilizer are:bacteria (Rhizobium spp., Azospirillum, Azotobacter), fungi (microrhizae like glomus), blue - green algae or cyanobacteria (anabena, nostoc etc.) and azolla (a fern containing symbiotic anabena azallae. Biofertilizer are products of elected valuable live microorganism, which help to improve plant growth and productivity mainly through supply of plant nutrients. Biofertilizer are also known as microbial inoculants or bio inoculants (Chen and Alexander, 1973; Moffett et al., 1983).

Synthetic/chemical manure not only provides essential nutrients to food crops but also provides simply available manner. So, these fertilizers can rapidly improve the increase and efficiency of food crops and are quick to gain popularity. However broad use 
of such fertilizer leads to serious concerns. Nitrate leakage and exterior/ soil water toxic waste due to augmented use of fertilizer is straight linked to human health problems. Likewise, fresh water pollution through chemical fertilizer/fertilizer remains be single of the main cause of eutrophication

Organisms to be often used while biofertilizers component be nitrogen fixers $(\mathrm{N}-$ fixer), potassium solubilizer (ksolubilizer) and phosphorus solubilizer by the formulation of mold and fungi. Nearly all of the bacteria included in biofertilizer include a close association through plant roots. Rhizobium has symbiotic interaction by legume roots and rhizobacteria in habit on roots surface or in rhizosphere soil. The phospho- microorganism mainly bacteria and fungi make insoluble phosphorus available to the plants (Gupta, 2004).

A number of reports include examine the different bacterial species to solubilizer insoluble organic phosphate compounds, such as tricalcium phosphate, dicalcium phosphate, hydroxyapatite, and rock phosphate. Among bacterial genera with this capacity are Pseudomonas, Bacillus, Rhizobium, Burkholderia, Achromobacter, Agrobacterium, Micrococcus, Aereobacter, Flavobacterium and Erwin a.. There are considerable populations of phosphate solubilizing bacteria in soil and in plant rhizospheres (Wani and Lee, 2002).

\section{Materials and methods}

\section{Isolation of Azotobacter species from soil sample}

Rhizospheric microbes were isolated from soil that were composed from CMBT lab (Bhopal).and inoculate in Ashby agar medium and was incubate at 24 hrs. Colony trait of arbitrarily isolated colonies was recorded. Gram staining was performed.

\section{Biochemical characterization}

Chosen colonies were more characterize for a variety of biochemical test as well as Catalase test activity sugar fermentation test hydrogen sulphide test in dole production test amylase test casein test etc.

\section{Fermentation}

Prepare Modified Ashby's medium contain Tryptone, Yeast Extract, Nacl Divide it in different bottles and sterilized it by autoclaving it for $15 \mathrm{~min}$. Now inoculate the medium with the help of inoculating loop using Bacillus microbes from the agar slant.. Keep warm the broth at the $35^{\circ} \mathrm{C}$ for 15 days for the process of fermentation.

The exhausted medium is centrifuged at $2000 \mathrm{rpm}$ for about 30 minutes. During the centrifugation, the mycelia fragments and spores settle down at the bottom of the centrifuge tube. The clear solution is separated from the tube and treated with $6 \mathrm{~N}$ $\mathrm{HCl}$ to reduce the $\mathrm{pH}$ to 3 . This acidified solution is transfer to a separating funnel and treated with ethyl ether. This solution is shaken well at $4^{\circ} \mathrm{C}$ for about one hour.

The IAA gets dissolved in the ether the fraction of ether is separated from the separating funnel and its volume is reduced to $1 / 4$ of the original volume of ether. The concentrated ether fraction is treated with an equal volume of sodium bicarbonate solution in order to extract more Auxin. This process is repeated for 2-3 times. The bicarbonate fraction is again treated with $6 \mathrm{~N}$ HCL to acidify the bicarbonate fraction. The resulting solution is treated with ethyl ether which dissolves more IAA from bicarbonate fraction. This process repeated 2 or 3 times to draw more IAA. The ethyl ether fraction contains IAA. It is concentrated by exposing it to air to gate a powder of IAA. It has mixture of different types of Auxin. They are separated by chromatography. 


\section{Quantification of Auxin}

A sample of isolated Auxin is treated with Salkowski reagent. It gives feature coloration, which indicates the presence of Auxin in the solution.

\section{Qualitative analysis of IAA}

Thin layer chromatography employed for the separation of different Auxin. Isopropanol-ammonia-water is used as a solvent for the chromatographic separation of Auxin.

\section{Result and Discussion}

A Catalase positive culture will produced bubbles of oxygen within one minutes after addition of $\mathrm{H}_{2} \mathrm{O}_{2}$. All the tube show positive



Fig: Catalase

Positive result show - Gas production + colour change of media from red to yellow Negative result show - No change of media colour

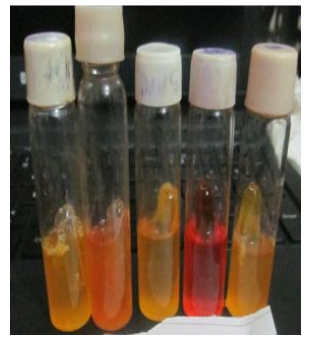

Fig: Fermentation of carbohydrate
Hydrogen sulfide, a colorless gas, when produced reacts with the metal salt (ferrous sulfate)) forming visible. The production of hydrogen sulfide from cysteine and sodium thiosulfate $\left(\mathrm{Na}_{2} \mathrm{~S}_{2} \mathrm{O}_{3}\right)$ takes place

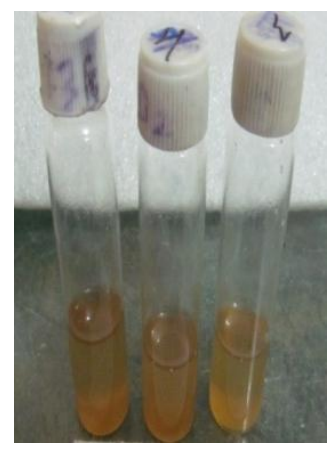

Fig: hydrogen sulphide test

Development of a cherry (deep) red color in the top layer of the tube Take 5 tubes 123 tubes were positive and 45 were negative

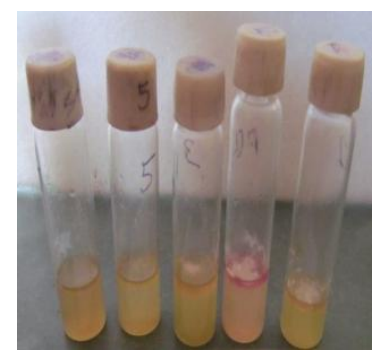

Fig: indole test

Starch in the presence of iodine produces a dark-blue coloration of the medium, and a yellow zone around a colony in an otherwise blue medium indicates amylolytic activity.

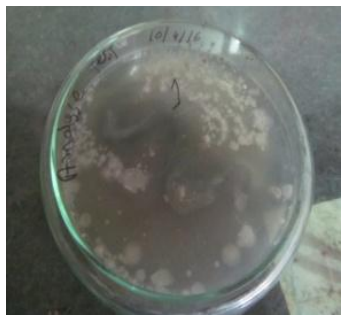

Fig: amylase test

Formation of a clear zone adjacent to the bacterial growth, after inoculation and 
incubation of agar plate cultures, is an evidence of casein hydrolysis

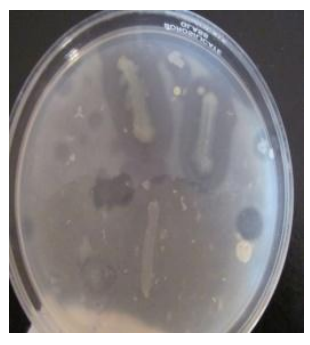

Fig: casein test

\section{Microbial identification using software}

On the basis of results of the gram's staining, growth on selective and differential media and biochemical analysis the isolated bacterial from sample sample $S_{1}, S_{2}, S_{3}, S_{4}$, s5 of soil identified using the software PIBWIN.

In conclusions, the result of the present study highlighted to nitrogen fixing bacteria as of rhizospheric soil be able to be simply isolated and might be exploited for confined cultivation use. This study indicates to azotobacter spp. exacting possesses the capability to manufacture high nitrogen in culture medium. This and the other isolates have possible for employ as plant biofertilizer or bioenhancer for the plant growth development though, additional study to determine the competence of the best isolate in situ, and mycorrhiza or plant connection is certainly needed.

Table.1 Identification of isolated culture from sample

\begin{tabular}{|c|c|l|}
\hline S.No. & Bacteria ID & \multicolumn{1}{|c|}{ Identified Bacteria } \\
\hline 1 & S-1 & Azotobacter nigricans \\
\hline 2 & S-2 & Azotobacter sp. \\
\hline 3 & S-3 & Azotobacter sp. \\
\hline 4 & S-4 & Azotobacter tropicalir \\
\hline 5 & S-5 & Azotobacter sp. \\
\hline
\end{tabular}

Table.2 Quantities estimation of Azotobacter

\begin{tabular}{|l|l|}
\hline Concentration & Absorbance \\
\hline 20 & 0.445 \\
\hline 40 & 0.657 \\
\hline 60 & 0.873 \\
\hline 80 & 1.067 \\
\hline 100 & 1.267 \\
\hline
\end{tabular}

Table.3 Bioassay of fermented Azotobacter:

\begin{tabular}{|r|l|c|c|}
\hline S.No. & Sample & Root lenth $(\mathrm{cm})$ & Shoot length $(\mathrm{cm})$ \\
\hline 1 & S-1 & 11 & 12 \\
\hline 2 & S-2 & 8 & 10 \\
\hline 3 & Standard & 6 & 10 \\
\hline 4 & Control & 5 & 5 \\
\hline
\end{tabular}


Fig.1 Quantification of IAA

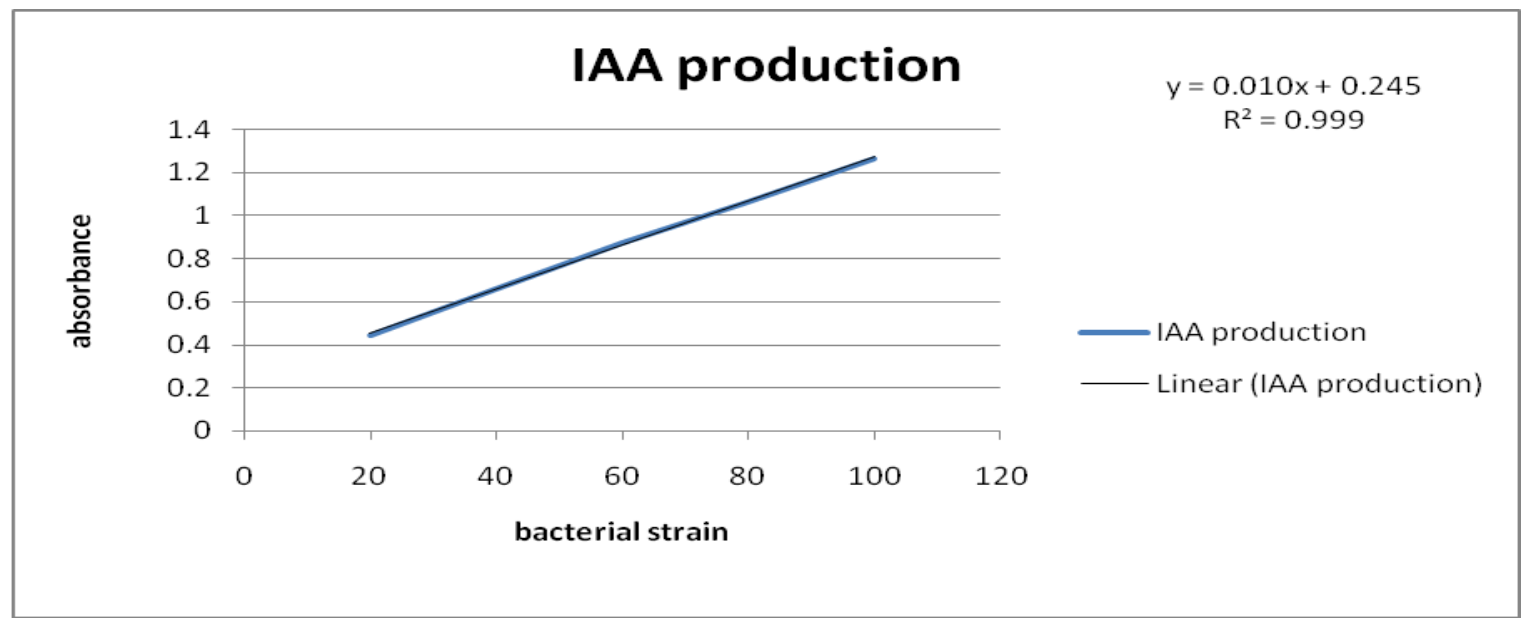

Fig.2 Production of IAA from two samples

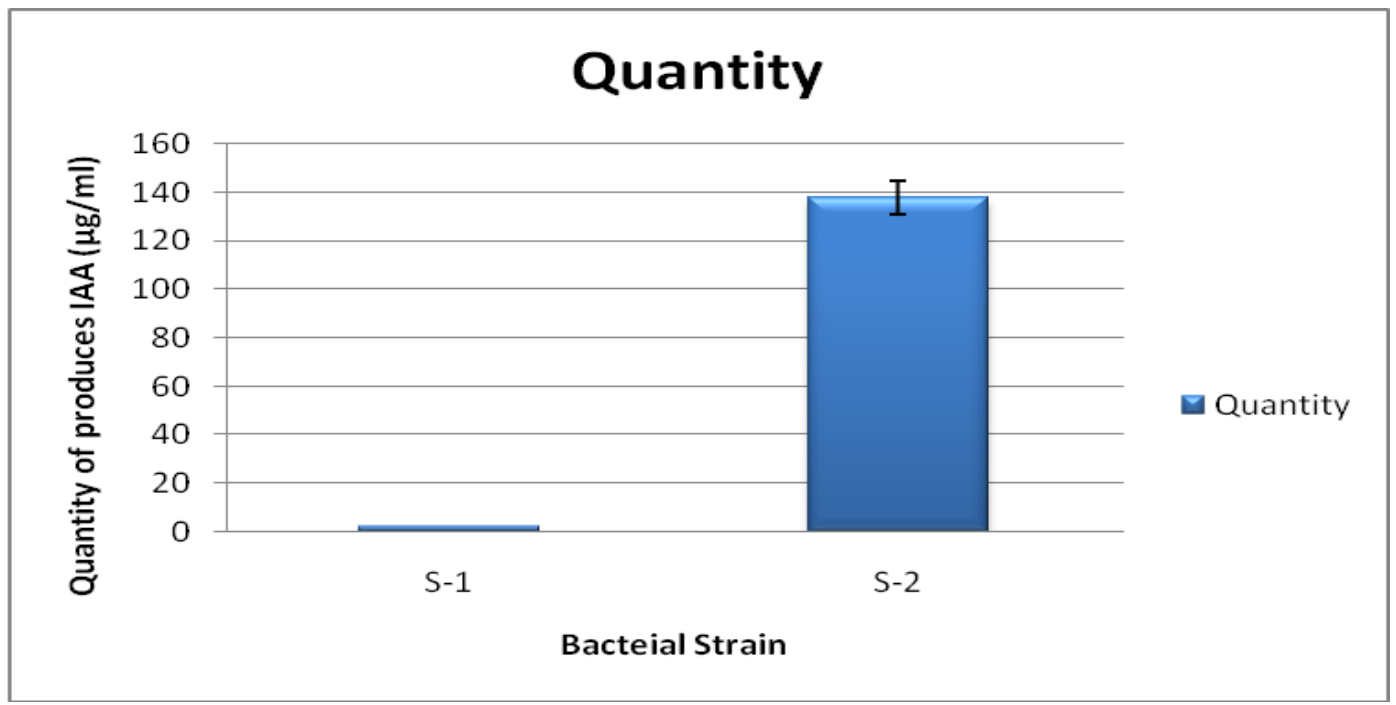

Bioassay of produced IAA

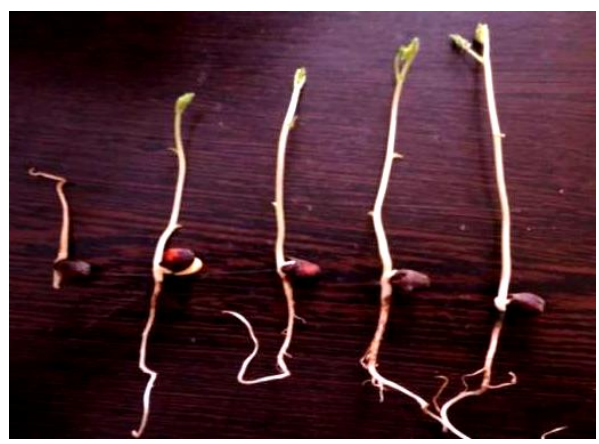


Four samples of rhizoflora of soil, S1, S2, S3 and S4 s5are analyze by a variety of pysico-chemical parameter as well as microbial study have too be complete. Azotobacter has many dissimilar effects, as nitrogen fixation and produced all Auxin do, such as inducing cell elongation and cell divisions with all following results for plant enlargement and growth.

\section{References}

Chen M, Alexander M. 1973. Survival of soil bacteria during prolonged desiccation. Soil Biol. Biochem. 5:213-221.

Moffett M.L, Giles JE, Wood BA.1983.
Survival of Pseudomonas solanacearum biovars 2 and 3 in soil: effect of moisture and soil type. Soil Biol. Biochem 15:587-591.

Gupta A.K. 2004. The complete technology book on biofertilizers and organic farming. National Institute of Industrial Research Press. India.

Wani, S.P. and Lee K.K., 2002.Population dynamics of nitrogen fixing bacteria associated with pearl millet (P. americanum L.), In biotechnology of nitrogen fixation in the tropics, University of Pertanian, Malaysia, 2130 .

\section{How to cite this article:}

Sumanto Prasad Barat, Abhishek Gupta, Dharmendra Singh, Arpita Srivastav, Summit Kumar Srivastav, Ravi Kumar, Pooja Singh, Nikhat firdous and Neelam Soni. 2016. Production of Liquid Bio fertilizer by using Azotobacter Species and their Effect on Plant Growth. Int.J.Curr.Microbiol.App.Sci. 5(7): 654-659. doi: http://dx.doi.org/10.20546/ijcmas.2016.507.074 